\title{
IDENTIFICAÇÃO DO RISCO DA RESISTÊNCIA DE PSEUDOMONAS AERUGINOSA A ANTISSÉPTICOS EM UNIDADES DE EMERGÊNCIA: UMA REVISÃO DE LITERATURA
}

\author{
Luiza Gabrielle Tavares dos Santos ${ }^{1}$ \\ Maria da Conceição Alexandre Castro ${ }^{2}$
}

RESUMO: Introdução: A resistência bacteriana pode ocorrer como estratégia de defesa das bactérias. A bactéria Pseudomonas aeruginosa se sobressai entre o grupo de bactérias gram-negativas, pois constantemente está relacionada com altas taxas de morbimortalidade em pacientes na unidade de emergência. Objetivo: Identificar quais antissépticos utilizados na unidade de emergência promovem maior risco de colonização e resistência da Pseudomonas aeruginosa. Método: Trata-se de uma revisão integrativa da literatura realizada no período de março a julho de 2020. Resultados: Alguns antissépticos utilizados na unidade de emergência, como fenóis sintéticos, compostos quaternários de amônio, clorexidina e polihexametileno biguanida, não possuem boa eficácia contra a bactéria gram-negativa P. aeruginosa, primeira a manifestar fenótipos multirresistentes a muitos antimicrobianos. Conclusão: É cada vez mais crescente o risco da resistência de $P$. aeruginosa aos antissépticos. Onde a proliferação dessa bactéria na unidade de emergência, pode desencadear um quadro de infecção hospitalar no paciente, com complicações e óbito.

DESCRITORES: Antissépticos. Infecção Hospitalar. Pseudomonas aeruginosa.

ABSTRACT: Introduction: Bacterial resistance can occur as a defense strategy for bacteria. The bacterium Pseudomonas aeruginosa stands out among the group of gramnegative bacteria, as it is constantly related to high rates of morbidity and mortality in patients in the emergency unit. Objective: To identify which antiseptics used in the emergency unit promotes a greater risk of colonization and resistance of Pseudomonas aeruginosa. Method: This is an integrative literature review carried out from March to July 2020. Results: Some antiseptics used in the emergency unit, such as synthetic phenols, quaternary ammonium compounds, chlorhexidine and polyhexamethylene biguanide, do not have good efficacy against gram-negative bacteria $\mathrm{P}$. aeruginosa, the first to manifest multidrug-resistant phenotypes to many antimicrobials. Conclusion: The risk of $\mathrm{P}$. aeruginosa resistance to antiseptics is increasing. With the proliferation of

\footnotetext{
I Graduanda em Biomedicina. Centro Universitário Brasileiro - UNIBRA, Núcleo de Saúde. Recife, Pernambuco, Brasil. https://orcid.org/oooo-ooo2-6320-6642 - tavaresluiza568@gmail.com

2 Enfermeira, Especialista em Urgência e Emergência. Mestre em Biologia Parasitária. Doutoranda em Medicina Tropical - UFPE. Professora do curso de enfermagem do Centro Universitário Maurício de Nassau - UNINASSAU. Recife, Pernambuco, Brasil. https://orcid.org/oooo-ooo2-4908-4415 conceicaoalexandre.enf@hotmail.com.
} 
this bacterium in the emergency unit, it can trigger a picture of nosocomial infection in the patient, with complications and death.

DESCRIPTORS: Antiseptics.Hospital Infection. Pseudomonas aeruginosa.

\section{INTRODUÇÃO}

A resistência bacteriana é uma reação natural que ocorre como estratégia de defesa utilizada pelas bactérias, inativando o mecanismo de ação de alguns antimicrobianos. Estudos afirmam que o uso frequente de vários fármacos, sem que seja cumprido corretamente o tratamento prescrito, pode provocar um aumento desse quadro de resistência. O uso de antimicrobianos, como os antissépticos, sem o devido planejamento e com alta frequência contribui para o surgimento de microrganismos resistentes, essa condição está diretamente relacionada com as infecções causadas por bactérias, que pode interferir na segurança do paciente e no desenvolvimento de patógenos resistentes a múltiplos fármacos ${ }^{1,2}$.

Os microrganismos que sofrem mutações genéticas são referidos em muitos estudos como "superbactérias", pois essas mutações não só facilitam a multiplicação bacteriana como também bloqueiam o efetivo tratamento e cura de doenças e impedem que os antissépticos cumpram seu objetivo principal: a diminuição de microorganismos na pele e mucosas 3 . Em alguns ambientes hospitalares é possível observar a presença de Staphylococcus aureus resistente à meticilina (MRSA), Staphylococcus spp, Enterococcus faecalis, Acinetobacter baumannii, Streptococcus spp e Serratia spp, Pseudomonas aeruginosa e a Klebsiella pneumoniae, sendo esses microrganismos encontrados colonizados em muitos locais, inclusive na cavidade nasal, jalecos e na saliva de profissionais da área hospitalar, equipamentos médicos, antissépticos e até na contaminação de fontes comuns como a água ${ }^{4,5}$.

Alguns antissépticos bastante utilizados, como polihexametileno biguanida, possuem boa atividade em antibiofilme de bactérias gram-positivas, como $S$. aureus e $S$. epidermidis, porém baixa em bactérias gram-negativas, como a $P$. aeruginosa ${ }^{6}$. Os antissépticos precisam passar por alguns critérios, como preparação antimicrobiana, atendendo às exigências nacionais e internacionais. Os mais disponíveis e utilizados são os que possuem em suas composições substâncias como álcool, gluconato de clorexidina 
(CHG), iodo, iodóforos, paraclorometaxilenol e compostos de quaternário de amônio7. Entretanto, são bem mais eficazes em bactérias gram-positivas do que em bactérias gramnegativas ${ }^{8}$.

A bactéria Pseudomonas aeruginosa se destaca entre o grupo das bactérias gramnegativas, justamente por ser resistente a vários antibióticos e por sua capacidade de desenvolver rapidamente resistência a novos antimicrobianos, sendo uma das primeiras bactérias a manifestar fenótipos multirresistentes ${ }^{9}$. Assim, faz-se necessário identificar diretamente os possíveis riscos de contaminação e colonização de bactérias nas técnicas assépticas, principalmente em unidades de atendimento de emergências ${ }^{\mathrm{IO}, \mathrm{II}}$.

Na maioria dos hospitais não há a devida atenção aos antissépticos e aos cuidados de armazenamento (como não expor a luz ultravioleta e ao calor, armazená-los em recipientes fechados) e utilização desses produtos, possibilitando a decomposição química dos produtos e/ou contaminação destes, ocasionando infecções graves e/ou até mesmo fatais no paciente, pois, os produtos vão ter uma diminuição do seu poder bacteriostático e bactericida. Vale ressaltar, que as infecções hospitalares causadas por bactérias possuem grande influência no período de hospitalização do paciente, elevando o risco de septicemia e contribuindo para o aumento dos índices de morbimortalidade ${ }^{12,13}$.

Considerando que as infecções hospitalares ocorrem com uma frequência considerável, se faz necessário uma maior atenção aos produtos utilizados nas unidades de atendimento de emergências, bem como, identificar quais antissépticos promovem maior risco de colonização e quais as formas de resistência da bactéria Pseudomonas aeruginosa para burlar o mecanismo de ação dos antimicrobianos ${ }^{6,9,12}$.

\section{OBJETIVO}

O objetivo desta pesquisa é identificar quais antissépticos utilizados na unidade de emergência promovem maior risco de colonização e resistência da bactéria Pseudomonas aeruginosa.

\section{MÉTODOS}

Trata-se de uma revisão integrativa da literatura realizada no período de março a julho de 2020, nos sistemas informatizados Scientific Electronic Library Online 
(SCIELO), Literatura Latino-Americana e do Caribe em Ciências da Saúde (LILACS), Biblioteca Virtual de Saúde (BVS) e o PubMed. Foram estabelecidos como critérios de inclusão artigos publicados entre os anos de 2015 a 2020, nos idiomas português, inglês e espanhol. Utilizando os critérios de exclusão, para as publicações que não atenderam ao objetivo estabelecido nesta pesquisa, que abordavam sobre técnicas antissépticas no pósoperatório cirúrgico e técnicas antissépticas bucais em consultórios de odontologia.

Foram encontradas no total 238.477 publicações de acordo com os critérios de inclusão e exclusão e os descritores aplicados. Foram utilizados, para busca dos artigos, os seguintes descritores e suas combinações nas línguas portuguesa, inglesa e espanhola: "Antissépticos e Infecção Hospitalar", "Emergências e Bactérias", "Pseudomonas spp e Resistência e Antissépticos", "Pseudomonas aeruginosa" e "Resistência Bacteriana e Pseudomonas aeruginosa". Para leitura, foram selecionadas 199 publicações, sendo 89 analisadas e observou-se uma maior prevalência de relatos de caso e revisões sistemáticas da literatura. A maioria dos artigos analisados foram da língua portuguesa.

\section{RESULTADOS}

De acordo com os critérios adotados para compilação dos resultados da pesquisa, foi elaborado um quadro com as considerações das principais publicações analisadas referentes a antissépticos e a resistência bacteriana da $P$. aeruginosa:

Quadro I - Considerações das principais publicações analisadas.

\begin{tabular}{|c|c|c|c|}
\hline Autores / Ano & Título & Objetivo & Conclusão \\
\hline Coutinho et al. 2015 & $\begin{array}{c}\text { Avaliações } \\
\text { comparativas da } \\
\text { associação entre } \\
\text { antibióticos frente à } \\
\text { Pseudomonas } \\
\text { aeruginosa }\end{array}$ & $\begin{array}{c}\text { Avaliar as } \\
\text { atividades } \\
\text { microbiológicas e } \\
\text { comparar as } \\
\text { atividades } \\
\text { decorrentes da } \\
\text { associação entre } \\
\text { antibióticos que } \\
\text { atuam no mesmo } \\
\text { alvo e também } \\
\text { em alvos diferentes }\end{array}$ & $\begin{array}{l}\text { Que o uso de alguns } \\
\text { antibióticos em } \\
\text { associação podem } \\
\text { aumentar o } \\
\text { potencial } \\
\text { antimicrobiano }\end{array}$ \\
\hline
\end{tabular}




\begin{tabular}{|c|c|c|c|}
\hline & & $\begin{array}{l}\text { frente às cepas } \\
\text { bacterianas de } \\
\text { Pseudomonas } \\
\text { aeruginosa. }\end{array}$ & \\
\hline Gandee et al. 2015 & $\begin{array}{l}\text { A eficácia da } \\
\text { administração de } \\
\text { antibióticos } \\
\text { imediatamente e } \\
\text { tardiamente no } \\
\text { crescimento } \\
\text { bacteriano e a } \\
\text { produção de } \\
\text { biofilme de cepas } \\
\text { selecionadas de } \\
\text { Escherichia coli } \\
\text { uropatogênica e } \\
\text { Pseudomonas } \\
\text { aeruginosa }\end{array}$ & $\begin{array}{l}\text { Analisar se o rápido } \\
\text { crescimento do } \\
\text { biofilme protetor } \\
\text { pode ser responsável } \\
\text { pela ineficácia dos } \\
\text { antibióticos contra } \\
\text { bactérias } \\
\text { selecionadas }\end{array}$ & $\begin{array}{l}\text { Observou-se no } \\
\text { estudo que os } \\
\text { antibióticos podem } \\
\text { não ser muito } \\
\text { eficazes, pois, em } \\
\text { algumas situações o } \\
\text { antibiótico pode } \\
\text { estimular a } \\
\text { produção de } \\
\text { biofilme, como a } \\
\text { nitrofurantoína }\end{array}$ \\
\hline $\begin{array}{c}\text { Santos, Nogueira, } \\
\text { Mendonça 2015 }\end{array}$ & $\begin{array}{l}\text { Mecanismos de } \\
\text { resistência } \\
\text { antimicrobiana em } \\
\text { Pseudomonas } \\
\text { aeruginosa }\end{array}$ & $\begin{array}{l}\text { Compreender os } \\
\text { mecanismos que } \\
\text { levam a essa } \\
\text { resistência é de } \\
\text { extrema importância } \\
\text { para enfrentar as } \\
\text { infecções por } P \text {. } \\
\text { aeruginosa }\end{array}$ & $\begin{array}{l}\text { Os principais } \\
\text { mecanismos são as } \\
\text { enzimas beta- } \\
\text { lactamases, bombas } \\
\text { de efluxo, perda de } \\
\text { porinas e resistência } \\
\text { a fluoroquinolonas. }\end{array}$ \\
\hline Silva et al. 2015 & $\begin{array}{l}\text { Controle } \\
\text { microbiológicos de } \\
\text { antissépticos e } \\
\text { antimicrobianos } \\
\text { comercializados na } \\
\text { farmácia univag } \\
\text { frente à bactérias } \\
\text { gram-positivas e } \\
\text { negativas }\end{array}$ & $\begin{array}{l}\text { Efetuar um } \\
\text { levantamento sobre } \\
\text { a eficácia dos } \\
\text { antissépticos mais } \\
\text { utilizados para a } \\
\text { antissepsia das mãos } \\
\text { tanto em ambiente } \\
\text { doméstico como em } \\
\text { ambiente hospitalar }\end{array}$ & $\begin{array}{c}\text { A proliferação e } \\
\text { contaminação por } \\
\text { essas bactérias se } \\
\text { dão principalmente } \\
\text { através da falta de } \\
\text { higiene e } \\
\text { principalmente pela } \\
\text { desinformação da } \\
\text { população em geral. } \\
\text { E que o sabonete } \\
\text { antibacteriano } \\
\text { utilizados nos } \\
\text { ensaios laboratoriais }\end{array}$ \\
\hline
\end{tabular}




\begin{tabular}{|c|c|c|c|}
\hline & & & $\begin{array}{c}\text { foi totalmente } \\
\text { ineficaz contra } \\
\text { Staphylococcus aureus } \\
\text { e Pseudomonas } \\
\text { aeruginosa }\end{array}$ \\
\hline $\begin{array}{l}\text { Porto, Menezes, } \\
\text { Pimenta } 2016\end{array}$ & $\begin{array}{l}\text { Perfil da infecção } \\
\text { bacteriana em } \\
\text { ambiente hospitalar }\end{array}$ & $\begin{array}{c}\text { Analisar os } \\
\text { tratamentos } \\
\text { utilizados e os } \\
\text { desfechos de cura e } \\
\text { reincidências e } \\
\text { assim determinar o } \\
\text { perfil das infecções } \\
\text { bacterianas em } \\
\text { pacientes internados } \\
\text { em um hospital } \\
\text { público do } \\
\text { município de Patos } \\
\text { no Estado da Paraíba }\end{array}$ & $\begin{array}{c}\text { Não foi possível } \\
\text { observar os } \\
\text { principais } \\
\text { causadores das } \\
\text { infecções } \\
\text { relacionadas à } \\
\text { assistência à saúde } \\
\text { por causa do baixo } \\
\text { índice de } \\
\text { cultura/antibiogram } \\
\text { a }\end{array}$ \\
\hline $\begin{array}{c}\text { Fracarolli; Oliveira; } \\
\text { Marziale } \\
2017\end{array}$ & $\begin{array}{l}\text { Colonização } \\
\text { bacteriana e } \\
\text { resistência } \\
\text { antimicrobiana em } \\
\text { trabalhadores de } \\
\text { saúde: revisão } \\
\text { integrativa }\end{array}$ & $\begin{array}{c}\text { Analisar as } \\
\text { evidências } \\
\text { científicas } \\
\text { disponíveis na } \\
\text { literatura sobre os } \\
\text { microrganismos que } \\
\text { colonizam os } \\
\text { trabalhadores de } \\
\text { saúde e sua } \\
\text { associação com a } \\
\text { resistência a } \\
\text { antimicrobianos }\end{array}$ & $\begin{array}{c}\text { Concluiu-se que o } \\
\text { Staphylococcus aureus } \\
\text { é a principal } \\
\text { bactéria } \\
\text { colonizadora em } \\
\text { trabalhadores da } \\
\text { saúde e que é } \\
\text { bastante resistente a } \\
\text { beta-lactâmicos }\end{array}$ \\
\hline Rossini et al. 2017 & $\begin{array}{c}\text { Testes } \\
\text { microbiológicos de } \\
\text { dispositivos } \\
\text { utilizados na } \\
\text { manutenção de } \\
\text { cateteres venosos } \\
\text { periféricos }\end{array}$ & $\begin{array}{c}\text { Avaliar o uso de } \\
\text { cateteres venosos } \\
\text { periféricos com base } \\
\text { em análises } \\
\text { microbiológicas } \\
\text { de dispositivos }\end{array}$ & $\begin{array}{l}\text { Que é importante } \\
\text { enfatizar a } \\
\text { resistência aos } \\
\text { carbapenêmicos em } \\
\text { amostras de } \\
\text { dispositivos e } \\
\text { reforçar o cuidado } \\
\text { na manutenção } \\
\text { biológica do } \\
\text { ambiente }\end{array}$ \\
\hline
\end{tabular}




\begin{tabular}{|c|c|c|c|}
\hline $\begin{array}{l}\text { Silva, Mançano, } \\
\text { Picão 2017 }\end{array}$ & $\begin{array}{c}\text { Cronologia da } \\
\text { emergência global } \\
\text { de carbapenemases } \\
\text { em bacilos gram- } \\
\text { negativos }\end{array}$ & $\begin{array}{c}\text { Fazer um } \\
\text { levantamento das } \\
\text { carbapenemases já } \\
\text { descritas em } \\
\text { diversas espécies de } \\
\text { bacilos gram- } \\
\text { negativos com } \\
\text { ênfase em suas } \\
\text { primeiras descrições }\end{array}$ & $\begin{array}{l}\text { Concluiu-se que } \\
\text { essas enzimas têm } \\
\text { impossibilitado o } \\
\text { tratamento de } \\
\text { várias infecções e } \\
\text { um dos motivos é } \\
\text { sua disseminação } \\
\text { que tomou } \\
\text { proporções globais }\end{array}$ \\
\hline $\begin{array}{c}\text { Volkart, Spagiari, } \\
\text { Bizani } 2017\end{array}$ & $\begin{array}{l}\text { Avaliação da } \\
\text { susceptibilidade e } \\
\text { resistência } \\
\text { bacteriana aos } \\
\text { agentes } \\
\text { controladores do } \\
\text { crescimento de uso } \\
\text { hospitalar e } \\
\text { industrial }\end{array}$ & $\begin{array}{c}\text { Estudar o } \\
\text { comportamento e a } \\
\text { resistência de } \\
\text { microrganismos } \\
\text { frente à ação de } \\
\text { agentes químicos } \\
\text { controladores de } \\
\text { crescimento e } \\
\text { determinar quais } \\
\text { concentrações das } \\
\text { substâncias } \\
\text { conseguem retardar } \\
\text { ou inativar o } \\
\text { crescimento }\end{array}$ & $\begin{array}{c}\text { Concluiu-se que os } \\
\text { desinfetantes mais } \\
\text { utilizados e } \\
\text { disponíveis no } \\
\text { mercado podem ter } \\
\text { seu mecanismo de } \\
\text { ação mudado de } \\
\text { acordo com a forma } \\
\text { de uso }\end{array}$ \\
\hline Magdaleno 2018 & $\begin{array}{l}\text { Uso ideal de } \\
\text { antissépticos no } \\
\text { ambiente intra e } \\
\text { extra-hospitalar }\end{array}$ & $\begin{array}{l}\text { Determinar como os } \\
\text { agentes devem ser } \\
\text { usados de acordo } \\
\text { com suas } \\
\text { características } \\
\text { antissépticos em } \\
\text { ambientes } \\
\text { hospitalares e } \\
\text { comunitários }\end{array}$ & $\begin{array}{l}\text { O antisséptico } \\
\text { escolhido não vai } \\
\text { depender apenas da } \\
\text { sua composição } \\
\text { química, mas } \\
\text { também da } \\
\text { aplicação, do } \\
\text { armazenamento e } \\
\text { da não realização } \\
\text { das recomendações } \\
\text { de antes e após o } \\
\text { uso do mesmo }\end{array}$ \\
\hline Ribeiro et al. 2018 & $\begin{array}{l}\text { Pseudomonas } \\
\text { aeruginosa na UTI: } \\
\text { prevalência, perfil } \\
\text { de resistência e } \\
\text { consumo de } \\
\text { antimicrobianos }\end{array}$ & $\begin{array}{c}\text { Monitorar o } \\
\text { consumo de } \\
\text { antibióticos, } \\
\text { especialmente em } \\
\text { ambiente hospitalar, } \\
\text { para evitar o } \\
\text { desenvolvimento de }\end{array}$ & $\begin{array}{l}\text { Concluiu-se que o } \\
\text { monitoramento do } \\
\text { consumo de } \\
\text { antimicrobianos e } \\
\text { de microrganismos } \\
\text { resistentes é de } \\
\text { extrema }\end{array}$ \\
\hline
\end{tabular}




\begin{tabular}{|c|c|c|c|}
\hline & & $\begin{array}{c}\text { resistência e } \\
\text { melhorar a eficácia } \\
\text { terapêutica dessas } \\
\text { drogas contra } P \text {. } \\
\text { aeruginosa }\end{array}$ & $\begin{array}{c}\text { necessidade para } \\
\text { reforçar o combate a } \\
\text { resistência } \\
\text { bacteriana }\end{array}$ \\
\hline Lima 2019 & $\begin{array}{l}\text { Carbapenemases } \\
\text { novas ou } \\
\text { emergentes em } \\
\text { Pseudomonas } \\
\text { aeruginosa }\end{array}$ & $\begin{array}{c}\text { Caracterizar } \\
\text { carbapenemases } \\
\text { novas ou emergentes } \\
\text { e seu contexto } \\
\text { genético em } P \text {. } \\
\text { aeruginosa }\end{array}$ & $\begin{array}{l}\text { Alguns isolados } \\
\text { foram possíveis } \\
\text { observar potenciais } \\
\text { novos genes de } \\
\text { carbapenemases em } \\
\text { isolados de } \\
\text { Pseudomonas } \\
\text { aeruginosa de origem } \\
\text { cromossômica }\end{array}$ \\
\hline $\begin{array}{c}\text { Nascimento et al. } \\
2019\end{array}$ & $\begin{array}{l}\text { Inferência de rede } \\
\text { regulatória de genes } \\
\text { e análise de } \\
\text { multirresistente } \\
\text { Pseudomonas } \\
\text { aeruginosa }\end{array}$ & $\begin{array}{c}\text { Reconstruir o GRN } \\
\text { da P. aeruginosa } \\
\text { resistente (MDR) e } \\
\text { analisar sua } \\
\text { propriedades } \\
\text { topológicas } \\
\text { P. aeruginosa } \\
\text { multiresistente e } \\
\text { analisar }\end{array}$ & $\begin{array}{l}\text { Essa reconstrução } \\
\text { contribuiu para o } \\
\text { aumento da } \\
\text { compreensão do } \\
\text { comportamento da } \\
\text { bactéria }\end{array}$ \\
\hline Zarza et al. 2019 & $\begin{array}{c}\text { Pseudomonas } \\
\text { aeruginosa: } \\
\text { Patogenicidade e } \\
\text { resistência a ação } \\
\text { antimicrobiana na } \\
\text { infecção do trato } \\
\text { urinário }\end{array}$ & $\begin{array}{c}\text { Analisar a } \\
\text { taxonomia, } \\
\text { patogenicidade e } \\
\text { mecanismos e genes } \\
\text { de resistência da } P . \\
\text { aeruginosa e os } \\
\text { fatores } \\
\text { microambientais das } \\
\text { infecções urinárias } \\
\text { produzidas }\end{array}$ & $\begin{array}{c}\text { Concluiu-se que se } \\
\text { deve repensar o uso } \\
\text { apropriado e } \\
\text { inapropriado de } \\
\text { antimicrobianos e } \\
\text { incentivar pesquisas } \\
\text { para novas } \\
\text { alternativas } \\
\text { terapêuticas, além } \\
\text { disso, incentivar } \\
\text { estudos para o } \\
\text { conhecimento dos } \\
\text { fatores de } \\
\text { patogenicidade e } \\
\text { multirresistência }\end{array}$ \\
\hline Barros et al. 2020 & $\begin{array}{l}\text { Impacto financeiro } \\
\text { da } \\
\text { antibioticoterapia }\end{array}$ & $\begin{array}{l}\text { Analisar os custos } \\
\text { financeiros da } \\
\text { terapia com }\end{array}$ & $\begin{array}{l}\text { Observou-se uma } \\
\text { prevalência de } \\
\text { resistência múltipla }\end{array}$ \\
\hline
\end{tabular}




\begin{tabular}{|c|c|c|c|}
\hline & $\begin{array}{c}\text { na resistência } \\
\text { a vários } \\
\text { medicamentos } \\
\text { bacterianos em um } \\
\text { hospital de } \\
\text { emergência em } \\
\text { Pernambuco, Brasil }\end{array}$ & $\begin{array}{c}\text { antibióticos } \\
\text { contra resistência } \\
\text { bacteriana em } \\
\text { hospital público de } \\
\text { alta complexidade } \\
\text { do Agreste } \\
\text { Pernambucano }\end{array}$ & $\begin{array}{c}\text { em homens idosos, } \\
\text { mesmo após a } \\
\text { última opção de } \\
\text { antibiótico, e, entre } \\
\text { as gram negativas, } \\
\text { se sobressaíram a } \\
\text { Citrobacter spp., } \\
\text { Pseudomonas spp., e } \\
\text { Enterobacter spp. }\end{array}$ \\
\hline
\end{tabular}

Fonte: Elaboração das autoras, 2020.

\section{DISCUSSÃO}

No Brasil, estima-se o surgimento de 600 mil novos casos de indivíduos acometidos por infecções bacterianas resistentes por $\mathrm{ano}^{\mathrm{i4}}$. Este problema não é preocupante apenas no Brasil, como demonstra um estudo realizado na Europa, onde foi estimado um percentual de $44 \%$ de mortes relacionadas a infecções por essas bactérias patogênicas, como Pseudomonas aeruginosa, Escherichia coli e Staphylococcus aureus, reforçando que esse é um problema de saúde mundialis,16. A P. aeruginosa é uma das bactérias mais identificadas, por ser uma ameaça crescente à saúde global, derivando no aumento alarmante da prevalência de infecções crônicas e nosocomiais, já que sua resistência a carbapenêmicos chega a ser de $60 \%$, e, as resistências naturais a vários tipos de antibióticos e antissépticos, justificam sua presença no ambiente hospitalar ${ }^{17}$.

A $P$. aeruginosa se adapta rápido às condições nutricionais do ambiente, da umidade e da temperatura. Devido a essa habilidade, consegue infectar utensílios e equipamentos hospitalares, assim como soluções antissépticas, fazendo estes lhe servirem de reservatório, pois, se tornam resistentes a diversos produtos químicos. Possibilitando sua permanência por longos períodos nos ambientes úmidos ${ }^{18}$.

Devido aos seus mecanismos de resistência como produção de enzimas, genes, adesinas, proteínas, proteínas porinas, flagelos e lipopolissacarídeos, a P. aeruginosa burla os mecanismos de ação dos antimicrobianos, modificando a estrutura química dos fármacos, impossibilitando a ação esperada do fármaco. Além disso, esta bactéria tem grande resistência aos antissépticos que possuem alguns elementos químicos específicos 
em suas composições, elementos esses que estão presentes na maioria dos antissépticos, como fenol e quaternários de amônio ${ }^{19}$.

A baixa eficácia desses compostos químicos pode configurar aos antissépticos uma ineficácia. A forma de resistência encontrada pelos bacilos da P. aeruginosa a amônio quaternário foi o mais observado na maioria dos estudos, pois estes formam mecanismos de resistência mediado por bombas de efluxo. Entre os isolados clínicos de P. aeruginosa, observou-se que os sistemas de efluxo MexAB-OprM e MexEF-OprN e cefalosporinase cromossômica AmpC (adenosina 3',5'-monofosfato cíclico) não são afetados pelos inibidores clinicamente disponíveis ${ }^{16}$.

Infelizmente, ainda não existe um antisséptico que atenda a todas as necessidades. Alguns são utilizados de forma padrão no cotidiano em serviços de saúde em todo o mundo, como o álcool a 70\% e clorexidina. A Clorexidina, por exemplo, mata os microrganismos de uma forma bastante lenta e não é eficiente contra a $P$. aeruginosa, pois, a bactéria desenvolve resistência rapidamente a esse antisséptico ${ }^{18,20,21}$.

Além do uso de antissépticos e das técnicas antissépticas, como a higienização das mãos, é importante destacar a utilização dos EPI's (Equipamentos de proteção individual) para a prevenção de infecções hospitalares bacterianas, como o uso das luvas, que é um procedimento padrão, porque minimizam os riscos de infecções intrahospitalares e cruzadas. Visto que, as luvas descartáveis não estéreis podem ser contaminadas com uma gama de bactérias. Principalmente, porque elas são utilizadas normalmente para procedimentos envolvendo mucosas. As mãos dos profissionais podem ser carreadores de infecções cruzadas, o que dificulta ainda mais a ação efetiva dos antissépticos ${ }^{18,20,21}$.

Apesar dos antimicrobianos possuírem mecanismo de ação diferente, uma exposição indiscriminada e/ou o contato com pacientes acometidos por diversos tipos de infecção podem admitir que uma resistência seja estabelecida. As mutações espontâneas e recombinações gênicas possuem uma grande contribuição para a formação da resistência e de uma variabilidade genética, surgindo às cepas bacterianas de maior resistência. Com isso os antimicrobianos não possuem mais a mesma funcionalidade ${ }^{22}$. 
Alguns dos antissépticos muito utilizados nas unidades de emergências, incluindo iodóforos (como o polivinilpirrolidona-iodo), fenóis sintéticos, compostos quaternários de amônio, clorexidina e polihexametileno biguanida, possuem boa atividade anti-filme de bactérias gram-positivas, como a S. aureus e S. epidermidis, porém baixa em bactérias gram-negativas, como a P. aeruginosa, pois, o biofilme deste do microrganismo favorece o desenvolvimento de infecções crônicas, como infecções de feridas e otites. Este complicado cenário da multirresistência bacteriana se torna um desafio no desenvolvimento de novos antimicrobianos eficazes ${ }^{6}$.

Ressalta-se que os riscos de um paciente colonizado por bactérias multirresistentes vão além dos altos índices de morbidade e mortalidade e do tempo de internação do paciente, também estão associados à alta susceptibilidade de infecções posteriores, favorecendo, mesmo sem o devido conhecimento, a disseminação desses microrganismos multirresistentes ${ }^{23,24}$.

Durante o processo de infecção, a $P$. aeruginosa pode se apresentar com um fenótipo mais virulento e se utilizar de mecanismos, como nadar através dos flagelos e espasmos que estão diretamente ligados a pili dessa bactéria, que aumentam os seus fatores patogênicos. O paciente acometido por esta infecção sofre um grande ataque de citotoxinas produzidas pela bactéria. Enquanto isso, o organismo do paciente procura encontrar respostas imunológicas para esse ataque, o que demanda muito desse organismo, já debilitado ${ }^{23}$.

Identificar quando uma infecção está acometendo o paciente é um grande desafio nas unidades de emergências, pois os sintomas e sinais clínicos de uma infecção são muitas vezes subjetivos e com várias possíveis causas para seu início e disseminação. Demandando por vezes tempo, até que seja estabelecido um diagnóstico diferencial ${ }^{25}$.

O controle dos riscos das infecções bacterianas relacionadas aos serviços de saúde, em especial na unidade de emergência, porta de entrada do complexo hospitalar, deve ser realizado de forma contínua. Devem ser adotadas medidas que possibilitem evitar fatores predisponentes e confortáveis para que as bactérias se mantenham proliferantes, e, assim, propiciar a diminuição da incidência de colonização e contaminação por P. aeruginosa e outros microrganismos. Para tal, é imprescindível a 
atuação da equipe multidisciplinar nos serviços de saúde com cuidado especializado e estratégias de educação em saúde que contribuam para cura da doença do paciente ${ }^{\mathrm{Io,I}}$.

\section{CONCLUSÃO}

O risco da resistência da Pseudomonas aeruginosa aos antissépticos utilizados em unidades emergências é cada vez mais acentuado, podendo a proliferação dessa bactéria desencadear um quadro de infecção no paciente com complicações e óbito. Onde que antissépticos como clorexidina e quaternários de amônio, quando em contato constante com a $P$. aeruginosa conferem resistência a ela, evidenciando-se a necessidade do uso prudente desses produtos. Levando em consideração os perigos de uma infecção hospitalar e da multirresistência desses patógenos, se fazem necessárias ações educativas para a equipe de saúde, principalmente, para os atuantes nas unidades de emergência, com uso racional de antissépticos.

Vale acrescentar, a importância de pesquisas em laboratórios de microbiologia e serviços de saúde geral, que possibilitem aos profissionais o conhecimento necessário para evitar o uso de antissépticos que não possuem eficácia contra a $P$. aeruginosa, auxiliando no controle e na prevenção das infecções causadas por essa bactéria. Pois, as infecções e a resistência bacteriana são uma ameaça comum nos serviços de saúde.

\section{REFERÊNCIAS BIBLIOGRÁFICAS}

I. Franco JM, Mendes RC, Cabral FRF, Menezes CDA. O papel do farmacêutico frente à resistência bacteriana ocasionada pelo uso irracional de antimicrobianos. Semana Acadêmica. 2015; I (72):1-17.

2. Vasconcelos DV, Oliveira TB, Araújo LLN. O uso de escopo não hospitalar antimicrobiano e como atribuição do Conselho Farmacêutico de Controle de Infecção Hospitalar (CCIH). Rev Fasem. 20I6; 4(2):I-15.

3. Organização Mundial de saúde (OMS). Guidelines on Hand Hygiene in Health Care: First Global Patient Safety Challenge Clean Care Is Safer Care. Geneva: WHO. 2009. Disponível em: <https://www.who.int/gpsc/5may/tools/who_guidelineshandhygiene_summary.pdf $>$. Acesso em 20 ago 2020. 
4. European Centre For Disease Prevention And Control. Antimicrobial resistance surveillance in Europe 2014: Annual report of the European Antimicrobial Resistance Surveillance Network (EARS-Net). ECDC. 2015; 34-47.

5. Mahmoud AM, Albadawy HS, Bolis SM, Bilal NE, Ahmed AO, Ibrahim ME. Inducible clindamycin resistance and nasal carriage rates of Staphylococcus aureus among healthcare workers and community members. African Health Sciences. 2015; I5(3):I-6.

6. Ortega-Penã S, Hidalgo-González C, Robson MC, Krotzsch E. Efeitos microbicidas in vitro, anti-biofilme e citotóxicos de diferentes antissépticos comerciais. Int Wound J. 2017; I4: 470-9.

7. Hemani ML, Lepor H. Preparação da pele para a prevenção da infecção do sítio cirúrgico: qual o melhor agente ?. Rev in urol. 2009;II(4):190-195.

8. Murray PR, et al. Manual of clinical microbiology. Washington D.C.: American Society of Microbiology. 2007; 9: 100-130.

9. Fraimow HS, Tsigrelis C. Resistência antimicrobiana na unidade de terapia intensiva: mecanismos, epidemiologia e manejo de patógenos resistentes específicos. Crit Care Clin. 2011; 27(I):163-205.

ı. Bardossy AC, Zervos J, Zervos M. Preventing hospital-acquired infections in lowincome and middle income countries: Impact, gaps, and opportunities. Infect Dis Clin North Am 2016; 30(3):05-18. Disponível em: 〈http://www.sciencedirect.com/science/article/pii/> Acesso em: 04 ago. 2020.

II. Folgori L, Bernaschi P, Piga S, Carletti M, Cunha FP, Lara PH, et al. Healthcareassociated infections in pediatric and neonatal intensive care units: Impact of underlying risk factors and antimicrobial resistance on 30-Day case-fatality in Italy and Brazil. Infect Control Hosp Epidemiol. 2016; I-8.

12. Pittet D. Infection control and quality health care in the new millennium. Am J Infect Control. 2005; 33:258-267.

13. Streeter K, Katouli M. Pseudomonas aeruginosa: A review of their pathogenesis and prevalence in clinical settings and the environment. 2016; $2(\mathrm{I}): 25-32$.

I4. Singer M, et al. The third international consensus definitions for sepsis and septic Shock (Sepsis-3). 2016; 315(8):801-810.

15. Rhodes A, et al. Surviving sepsis campaign: International guidelines for management of sepsis and septic shock: 2016. Critical Care Medicine. 2017; 45(3): 486-455. 
16. Cassini A, Högberg LD, Plachouras D, Quattrocchi A, Hoxha A, Simonsen GS, et al. Attributable deaths and disability-adjusted life-years caused by infections with antibiotic-resistant bacteria in the EU and the European Economic Area in 2015: a population-level modelling analysis. Lancet Inf Diseases. 2019; 19(I):56-66.

17. Potron P, Poirel L, Nordmann L. Resistência de amplo espectro emergente em Pseudomonas aeruginosa e Acinetobacter baumannii : mecanismos e epidemiologia. Clinical Microbiol Inf. 2015; 45:568-585.

18. Silva M, Ning C, Ghanbar S, Zhanel G, Logsetty S, Liu S. Evidências de que o novo composto quaternário e seu derivado orgânico de $\mathrm{N}$-cloramina não selecionam mutantes resistentes de Pseudomonas aeruginosa. J Hosp Infect. 2015; 91(I):53-58.

19. Chatterjee M, Anju CP, Biswas L, Kumar VA, Mohan CG, Biswas R. Antibiotic resistance in Pseudomonas aeruginosa and alternative therapeutic options. International Journal of Medical Microbiology. 2016; 306:48-58.

20. Oliveira FP, et al. Prevalence, antimicrobial susceptibility, and clonal diversity of Pseudomonas aeruginosa in chronic wounds. Journal of Wound Ostomy Continence Nursing. 2017; 6:528-535.

2. Pires BMFB, et al. Monitoring and molecular characterization of Staphylococcus aureus isolated from chronic wounds. Advances in Skin \& Wound Care. 2018; I(8): 399405 .

22. Santos CHS, Piccoli RH, Tebaldi VMR. Atividade antimicrobiana de óleos essenciais e compostos isolados frente aos agentes patogênicos de origem clínica e alimentar. Rev Inst Adolfo Lutz. 2017; (76):17-19.

23. Winstanley C, O’brien S, Brockhurst MA. Adaptação evolutiva e diversificação de Pseudomonas aeruginosa nas infecções pulmonares crônicas da fibrose cística. Trends Microbiol. 2016. 24: 327-337.

24. Tseng WP, Chen YC, Chen SY, Chen SY, Chang SC. Risk for subsequent infection and mortality after hospitalization among patients with multidrug-resistant gramnegative bacteria colonization or infection. Ant Resist and Inf Control. 2018; 7:93.

25. Teles DKN, et. al. Característica dos óbitos por sepse no município de Aracaju. Sergipe: Ciência Biológicas e da Saúde Unit. 20I7; 4(I):I-I4. 